\title{
4919
}

\section{As potencialidades do estudo da imagem fotográfica na antropologia visual}

\section{Sofia Caldeira}

\begin{abstract}
Resumo:
Numa sociedade cada vez mais visual, torna-se compreensível que disciplinas como a antropologia tenham começado a manifestar um crescente interesse nas questões da visibilidade. Embora esta preocupação não seja exatamente recente, o problema de "O que fazer com a imagem?" tem sido fonte de constantes inquietações. Durante décadas, a antropologia visual continuou confinada a práticas tradicionalistas e limitativas, que viam as tecnologias visuais como meras ferramentas de pesquisa ou como modo de apresentar os seus estudos. Apesar disso, recentemente, abandonando a teimosia metodológica que limitava o estudo antropológico ao método malinowskiano, o estudo de imagens de variadas proveniências tem emergido como um campo válido para a imersão etnográfica, com o potencial de revelar processos percetuais, históricos e socioculturais.

Das infindáveis formas de produção imagética, centro-me neste ensaio nas potencialidades trazidas pela análise da imagem fotográfica vernacular. Tal como a própria análise imagética, necessariamente multidisciplinar e multimetodológica, também este ensaio vive do cruzamento de textos e pontos de vista, vindos de várias disciplinas.

O ensaio procura apontar algumas das potencialidades trazidas pelo uso de corpus imagéticos fotográficos, enfatizando as afinidades já existentes entre a atividade fotográfica e etnográfica. Do seu aparente caráter apodítico à sua visão necessariamente subjetiva, passando pela sua capacidade performativa - a fotografia tem o potencial de fornecer ao antropólogo material precioso para compreender, de modo não-intrusivo e da perspetiva do sujeito estudado, as mais variadas dinâmicas sociais.
\end{abstract}

Palavras-Chave: antropologia visual; fotografia; análise de imagem; metodologias. 


\section{Abstract:}

In an increasingly visual society, it becomes understandable that disciplines such as anthropology have started to show a growing interest in the questions of visibility. Although this concern is not exactly recent, the question of "What to do with the image?" has been a source of constant anxieties. For decades visual anthropology remained confined to traditionalist and limitative practices that understood visual technologies as mere research tools or as a way to present their studies. Nevertheless, recently, by abandoning the methodological stubbornness that limited anthropological study to the Malinowskian method, the study of images of varied provenances has emerged as a valid field for the ethnographic immersion, with the potential to reveal perceptual, historical and sociocultural processes.

From the countless forms of imagetic production, in this essay I focus on the potentialities brought by the analysis of the vernacular photographic image. Like image analysis itself, necessarily multidisciplinary and multi-methodological, also this essay emerges from the crossing of several texts and points of view, from various disciplines.

This essay intends to point some of the potentialities brought by the use of a photographic corpus, emphasizing the already existing affinities between the photographic and the ethnographic activities. From its apparent apodictic character to its necessarily subjective visions, passing by its performance capacity - photography has the potential to offer the anthropologist precious material to understand, in a nonintrusive way and from the perspective of the studied subject, the most diverse social dynamics.

Keywords: visual anthropology; photography; image analysis; methodologies.

Dizermos, hoje, que vivemos numa sociedade eminentemente visual tornou-se quase redundante. Uma multitude de imagens insere-se no fluxo da nossa experiência quotidiana, presente em praticamente todos os instantes das nossas vidas, parte integrante destas. Neste paradigma, torna-se compreensível, e até expectável, que disciplinas que se dedicam ao estudo da experiência sociocultural humana, como é o caso da antropologia, tenham começado a demonstrar um interesse crescente nas questões da visualidade e dos usos da imagem, vendo nestas uma potencial janela metafórica sobre a vida dos outros, uma fonte quase inesgotável de informação.

Este interesse pelo visual não é de todo um fenómeno recente, estando presente quase desde os primórdios da antropologia moderna e tendo desde cedo se estabelecido na subdisciplina da antropologia visual. Contudo, a questão de "O que fazer com a imagem?" foi sempre e continua ainda a ser fonte de inquietações constantes.

Aulas e livros introdutórios à disciplina apontam repetidamente três possíveis tipologias de trabalho dentro da antropologia visual: 1) o uso de técnicas de registo audiovisual como uma ferramenta para a pesquisa etnográfica tradicional, servindo-se da máquina 
fotográfica ou de filmar como um paralelo e um complemento ao diário de campo; 2) o uso dessas mesmas ferramentas audiovisuais como um modo de escrita, usando-as para a apresentação de estudos antropológicos sob a forma de filmes etnográficos, ensaios fotográficos, auxiliares de apresentações em palestras, ou como ilustrações em monografias; e, finalmente, 3) o estudo da imagem num sentido mais lato, como um objeto de pesquisa válido em si mesmo, abrindo a possibilidade de se debruçar sobre a análise de imagens produzidas por outros e até em contextos tipicamente entendidos como exteriores à antropologia (Augé \& Colleyn, 2008: 62-63). No entanto, na continuação destas introduções à antropologia visual, a terceira destas hipóteses raras vezes é aprofundada teórica e metodologicamente, sendo o discurso da disciplina, e a perceção geral sobre esta, dominado sobretudo pelo filme etnográfico (Morphy \& Banks, 1995: 5).

Este enfoque limitado e limitativo sobre o filme etnográfico deve-se em grande parte a uma relação de dependência identitária que a antropologia, enquanto disciplina, mantém ainda com o conceito malinowskiano de trabalho de campo. Quando, em 1922, Bronislaw Malinowski escreve a famosa introdução aos Argonautas do Pacífico Ocidental, ele redefine toda a noção até então existente de trabalho de campo e, por afinidade, do trabalho do antropólogo. A ideia romântica do antropólogo sozinho numa praia tropical, isolado dos seus pares e completamente imerso na vida da pequena aldeia nativa que tenciona estudar (Malinowski, 1997: 19), tornou-se central e definidora da antropologia. O seu método etnográfico, ainda hoje estudado, advogava uma permanência prolongada e ininterrupta entre os nativos, que permitisse ao antropólogo a imersão total no terreno e a participação no quotidiano estudado. Deste modo, Malinowski acreditava normalizar a sua presença no seio da comunidade, deixando de ser um "elemento perturbador" e podendo assim estudar a sua vida tribal, costumes e cerimónias, sem a perturbar e alterar (Malinowski, 1997: 22). Este modo de trabalho etnográfico traz também a possibilidade de uma "aprendizagem espontânea", a criação de saberes antropológicos por familiarização ou impregnação, que demove o investigador de projetar ideias e hipóteses pré-concebidas sobre a realidade social que observa (Augé \& Colleyn, 2008: 73-74), tornando-se assim os questionamentos e dilemas do etnógrafo parte integrante do método etnográfico (Augé \& Colleyn, 2008: 82).

O trabalho de campo etnográfico é tido ainda hoje como o método privilegiado da antropologia e o seu principal contributo académico (Augé \& Colleyn, 2004/2008: 7), definindo as suas próprias fronteiras académicas. Assim, a distinção central entre a antropologia e as restantes ciências sociais é vista como assentando não tanto nos tópicos estudados, que são comuns a variadas disciplinas, mas sobretudo no recurso 
ao trabalho de campo e no seu método de observação participante (Gupta e Ferguson, 1987: 2).

Contudo, a nossa experiência contemporânea dificilmente é equiparável com a realidade experienciada por Malinowski. Se já então era difícil conceber uma comunidade como verdadeiramente isolada e livre de quaisquer empréstimos culturais, hoje mais que nunca a cultura apresenta-se como liberta deste isolamento geográfico, transpondo facilmente fronteiras e interagindo com um sistema-mundo mais vasto. Os avanços do capitalismo global e, sobretudo, os avanços tecnológicos vêm minar a visão tradicionalista de campo antropológico, criando uma certa angústia metodológica que força a antropologia contemporânea a debruçar um olhar reflexivo sobre si mesma e a procurar reinventar-se.

Tal reinvenção não implica, no entanto, o abandono completo e radical das práticas de trabalho de campo, mas sim uma abertura à sua reconceptualização. O tradicional campo, geograficamente situado, passa a coabitar com outros campos, fontes de informação das quais o investigador é capaz de extrapolar conhecimentos sócioculturais. O espírito etnográfico clássico é assim adaptado ao estudo de variados média, conferindo-Ihes legitimidade antropológica (Coman \& Rothenbuhler, 2005: 1). Conceções tradicionais como a noção de alteridade deixam de ser associadas ao exotismo que marcou a antropologia clássica e moderna, e ressurgem como uma atitude mental do investigador sobre estes novos campos, que aborda e interroga com "espanto sistemático", questionando as suas próprias predefinições e predispondo-se para a descoberta e aprendizagem (Augé \& Colleyn, 2008: 17).

O foco é assim alterado, passando do estudo de "unidades sociais coerentes e de fraca amplitude", que Claude Rivière (2011: 17) via como objeto central da antropologia, para o estudo de temas, conceitos e hipóteses pertencentes à vasta base epistemológica da disciplina, visíveis nas mais variadas manifestações sociais. Temáticas tradicionalmente antropológicas, como a língua, o parentesco, as hierarquias sociais e políticas, os mitos e rituais, ou ainda, as representações e a performatividade do corpo podem ser estudadas fora do tradicional campo, através da aplicação de uma mentalidade etnográfica na análise de terrenos tão pouco ortodoxos como os média.

Assim, a já apontada terceira tipologia de trabalho da antropologia visual torna-se possível, expandindo o leque de objetos considerados passíveis de estudo antropológico a produções culturais previamente ignoradas: criações artísticas, eventos desportivos, bandas desenhadas, postais, vídeos caseiros, desenhos infantis, publicidade, design industrial, fotografia vernacular, e incontáveis outras possibilidades. A antropologia visual abre-se assim ao estudo de sistemas visuais, analisando as suas propriedades, as condições para a sua produção e interpretação, e as suas inter- 
relações com os sistemas sociais e políticos em que se inserem (Morphy \& Banks, 1999: 2), e pelos quais são influenciados e que simultaneamente influenciam. Utilizando imagens específicas como objeto e campo de estudo, a antropologia visual não se dedica propriamente ao visual em si mesmo, mas usa-o como modo de compreender uma série de relações socioculturais que se reificam nestas imagens (MacDougall, 1999: 288).

\section{A imagem fotográfica e as suas particularidades}

De entre todos estes possíveis objetos de estudo centro-me neste ensaio na produção fotográfica. É certo que tomar a imagem fotográfica como campo de estudo continua a ser uma afirmação simultaneamente demasiado vaga e demasiado ambiciosa. O próprio François Arago, citado por Benjamin (1999: 508), apontava já em 1839, no seu discurso aclamando a invenção do daguerreótipo, as inúmeras aplicações possíveis para a criação fotográfica - desde a criação artística, documental, histórica ou mesmo astrofísica - em tudo distintas nos seus usos e discursos (e assim também nas possibilidades que conheceriam dentro da antropologia visual). Assumir como campo tal vastidão seria como dizer, num paralelo com o trabalho etnográfico tradicional, "O meu campo é a Europa". Escrevo então este ensaio tendo em mente a produção fotográfica vernacular, e ciente de que, ainda assim, este continua a ser um objeto de estudo imensamente vasto.

A fotografia vernacular parece, à primeira vista, um terreno bastante afastado do tradicional objeto exótico e distante antropológico. Mais confortável nas suas delimitações académicas esteve a antropologia visual enquanto se debruçou apenas sobre a produção imagética dos mesmos povos que outrora estudava no terreno. Mas torna-se necessário quebrar estas limitações e ser capaz de adoptar como fotografia antropológica um conjunto de imagens que pode não ter sido criado com um intuito especificamente antropológico em mente, mas do qual conseguimos, no entanto, extrair informação sociovisual significativa e útil (Edwards, 1992: 13). Tais informações são extraídas ao aplicar criticamente a já referida mentalidade etnográfica aquando do estudo das imagens, olhando-as seriamente de modo cuidadoso e prolongado, considerando a sua composição visual e os seus efeitos próprios. A análise de uma fotografia, ou corpus fotográfico, parte assim sempre de um processo etnográfico de imersão e de descoberta.

A prática da fotografia vernacular encontra já, em si mesma, alguns paralelos com a antropologia e o método etnográfico. O foco da fotografia vernacular no quotidiano de gentes comuns evoca a ideia defendida em 1927 por Siegfred Kracauer (1993: 422), segundo a qual as "pequenas catástrofes" que compõem a vida quotidiana influenciam 
muito mais profundamente e continuamente a vida das pessoas do que os grandes eventos. Esta mesma ideia é central ao método etnográfico que, através de uma permanência prolongada na comunidade, procura poder presenciar não só os grandes momentos rituais mas também o seu quotidiano comum, os seus costumes, emoções e reações - aquilo que não se consegue recolher através de questionários ou documentos escritos e que Malinowski (1997: 31) intitulou de "imponderáveis da vida real", aspetos imprescindíveis para compreender uma sociedade.

Também através do recurso à análise da fotografia vernacular, a antropologia visual aproximou-se do desejo de quase invisibilidade latente no método malinowskiano. Mais do que uma presença normalizada e não perturbadora, o investigador está agora completamente ausente do momento criador da imagem. A fotografia oferece assim a possibilidade de entrever ritos eminentemente privados, como por exemplo ligados a dinâmicas familiares, vistos da perspetiva do próprio sujeito em estudo.

Um outro paralelo, desta vez já mais ténue e quase inconsciente, é estabelecido entre a função memorial da fotografia e a, hoje desacreditada, etnografia de urgência. André Bazin (1960: 4-8) relacionou a fotografia com os processos de embalsamação e mumificação, vendo nesta uma ferramenta para salvar a existência efémera da passagem do tempo, salvando-a da morte e do esquecimento, de forma muito semelhante ao modo como a etnografia de urgência tentava estudar e fixar as sociedades primitivas que acreditava destinadas a um inevitável desaparecimento.

Mas é sobretudo na própria imobilidade da fotografia que se centra a possibilidade para a tão necessária imersão prolongada no campo de estudo que marca a etnografia. Retirada do fluxo incessante da experiência quotidiana e livre dos constrangimentos temporais impostos por outros media, como o filme, a fotografia cria a possibilidade de um tempo próprio para a contemplação, permite ao investigador demorar o seu olhar sobre a imagem, analisando-a de um modo que seria impossível no fluxo da vida (Edwards, 1992: 7). Enquanto o fascínio e a curiosidade do investigador persistirem, este pode continuar o seu mergulho metafórico na imagem.

A fotografia, face a outras formas de produção imagética, apresenta-se como mais propícia ao estudo antropológico por parecer oferecer um acesso mais direto e não mediado, uma noção de ter-estado-lá barthesiana, à vida das pessoas e comunidades sob estudo. Esta ideia do realismo fotográfico, completamente enraizada no discurso fotográfico, surge não só devido às caraterísticas visuais da fotografia mas sobretudo graças à consciência da sua génese mecânica. Bazin (1960: 7-8) louvava a fotografia como a primeira forma de criação imagética formada de modo completamente automático, sem qualquer intervenção do homem (excepto na breve concessão que faz ao papel do fotógrafo na seleção do que fotografar), e era justamente desta "ausência 
humana" que emergia a superioridade fotográfica enquanto promessa de representação objetiva e realista.

A consciência desta produção automática afetou a nossa relação psicológica com a imagem fotográfica, à qual passamos a atribuir uma maior credibilidade, sendo forçados a admitir que o objeto que vemos representado na fotografia existiu realmente. A fotografia, sendo fruto de um efeito direto e causal da luz, que incide sobre uma superfície quimicamente sensibilizada, estabelece uma relação com o mundo real que não é simplesmente de semelhança visual, de iconicidade, mas que é também indexical - uma relação física e causal entre a coisa necessariamente real a que se refere a fotografia e o objeto que representa (Krauss, 1977a: 70), como que se tratasse de uma transferência ou um decalque do real. A semelhança fotográfica, segundo Charles S. Pierce (citado em Krauss, 1977b: 63), existe porque as fotografias são produzidas sob circunstâncias que as forçam fisicamente a corresponder, ponto-por-ponto, à natureza. Assim, Roland Barthes no início dos anos 80 (2009: 12-13) atribuiu à imagem fotográfica o estatuto de "mensagem sem código", por ver nesta não uma transformação ou codificação do real, mas sim o seu analogon perfeito.

A grande vantagem e caraterística distintiva da fotografia não está então na imagem em si mesma, na sua aparência estética de mimetismo, ou na sua capacidade informativa, mas sim na relação de contiguidade que estabelece com o mundo. Um desenho pode, muitas vezes, ser mais informativo ou uma pintura pode ser mais fiel cromaticamente, mas a fotografia afirma-se sempre como "o objeto em si mesmo", por muito desfocada, distorcida ou mesmo incompreensível que possa estar (Bazin, 1960: 8). E esta nossa relação com a imagem fotográfica enquanto medium privilegiado do realismo teima em manter-se. Mesmo perante a possibilidade de manipulação, acentuada pelo digital, somos inconscientemente compelidos a interagir com as fotografias e a encará-las relativamente seguros da sua autenticidade e realidade.

Graças à sua génese mecânica, a fotografia adquire uma impassibilidade que contrasta com a falibilidade, seletividade e subjetividade da visão humana. Walter Benjamin, no seu ensaio A Pequena História da Fotografia, publicado em 1931 (1999: 510-512), afirma que é distinta a natureza que a câmara vê daquela que o olho perceciona, encontrando na fotografia uma ferramenta para atingir o "inconsciente óptico". A câmara, tal como uma prótese freudiana, expande as capacidades da visão humana, permitindo ver eventos e momentos dos quais temos uma perceção incompleta. Atos tão simples como andar são compreendidos na minúcia de uma fração segundo isolada fotograficamente. Mas, sobretudo, a fotografia capta indiscriminadamente até as mais pequenas coisas que o acaso coloque frente à lente, apresentando a totalidade espacial do momento fotografado, mantendo num grau de igualdade todos os pequenos 
fragmentos da estrutura complexa do mundo real, seja o gesto de uma criança ou o detalhe do pavimento (Bazin, 1960: 8). A relação de contingência com o mundo tornase visível na fotografia, imprimindo nesta incontáveis detalhes e informações, muitas vezes ignorados pelo próprio fotógrafo no momento do clique, que mais tarde poderão ser redescobertos e reanalisados.

\section{A fotografia vernacular}

Mas por muito tentador que possa ser perder-se indefinidamente nas minúcias visuais da imagem fotográfica, há que relembrar que esta, para o antropólogo visual, não é um fim em si mesmo, mas um meio para abrir o nosso entendimento para questões mais latas da experiência humana. No início do século XX, com a popularização das câmaras pessoais Kodak e da estética do snapshot, a fotografia perdeu grande parte do seu caráter ritual, tornando-se parte integrante da vida comum e a sua criação quase um reflexo inconsciente. A sua circulação em contextos eminentemente sociais, envolvida em relações particulares e específicas, torna os seus significados histórica, social e culturalmente condicionados (Banks, 2001: 179). Como tal, a fotografia revela-se como um meio privilegiado para comunicar sobre cultura, vidas de pessoas e comunidades, as suas posições sociais, as suas crenças e experiências, enfim, a sua relação com o mundo.

A fotografia inseriu-se com especial ubiquidade nas práticas familiares, sendo utilizada como um auxiliar de memória nas mais variadas circunstâncias, domésticas ou rituais, desde pequenos momentos do quotidiano a aniversários, casamentos, férias, etc., sendo simultaneamente um documento fotográfico da unidade familiar e uma ferramenta para a construção dessa mesma unidade (Krauss, 1984: 56).

Pela sua vertente social a fotografia, enquanto objeto, adquire um caráter simbólico, tornando-se quase um artefacto de elevado valor sentimental. A relação do sujeito com a fotografia ecoa a relação deste com o objeto ou contexto fotografado, num discurso quase animista que revela reminiscências mágico-rituais, como as que se manifestam na nossa relutância em destruir fotografias de entes queridos (Mitchell, 1996: 73). Da observação desta relação muito pode ser aprendido pelo investigador.

Dadas as suas claras e limitadas funções sociais, grande parte das representações fotográficas vernaculares tendem a incidir sobre um leque de sujeitos, objetos e momentos relativamente limitados, que são fotografados usualmente de modo extremamente limitado e repetitivo - poses frontais, sujeitos ao centro, sorrisos postos (Krauss, 1984: 57). A experiência quotidiana da fotografia é assim determinada por uma série de convenções, quase sempre implícitas e adoptadas de modo inconsciente, que estabelecem os seus atributos estéticos e sociais (Stiegler, 2008: 196). Este recurso a 
convenções evoca o conceito de habitus de Pierre Bourdieu (Casanova, 1995), que refere justamente um uso sistemático e naturalizado de hábitos e práticas sociais, incutidos pela cultura e sociedade através de mecanismos difusos vários, como a educação, a convivência, a observação, etc. O habitus é assim estruturado pela sociedade, mas acaba simultaneamente por se tornar estruturante desta. Este habitus pode ser compreendido em vários níveis sociais, desde sociedades inteiras, classes, famílias e mesmo a nível individual: "(...) falar de habitus é estabelecer que o individual, e mesmo o pessoal, o subjetivo, é social, coletivo. O habitus é uma subjetividade socializada." (Bourdieu, citado por Casanova, 1995: 55) E expressa-se no indivíduo de forma reificada na sua dimensão corporal, nas suas ações, gestualidades ou mesmo modos de vestir. O corpo surge como um espelho do habitus, e como tal ferramentas como a fotografia, que fixam a dimensão espetacular da vida social, tornam-se incrivelmente úteis para poder estudá-lo. Existe uma dimensão quase performativa do habitus, que se espelha na representação fotográfica. Tal não implica, contudo, que os sujeitos estejam a representar cientes das implicações sociais dos seus atos. O habitus, tal como as convenções fotográficas atrás mencionadas, expressa-se de modo inconsciente e espontâneo, e é mais vivido do que conceptualizado. Embora importante, da análise do habitus não podemos esperar deduzir toda a complexidade das práticas sociais, justamente por este conceito não ser marcado pela regularidade de um "princípio legislativo", mas por incorporar uma certa abertura e indeterminação próprias que o tornam maleável (Casanova, 1995: 52-53).

\section{Metodologias visuais: produção, imagem e receção}

Não procurando este estudo ser um manual detalhado sobre como analisar uma fotografia passo-a-passo, apresenta-se antes como uma espécie de introdução, necessariamente breve e incompleta, às potencialidades e limitações deste campo de estudo antropológico que é a fotografia vernacular. O foco em metodologias assume, igualmente, um caráter superficial, por existirem muitos outros livros (Banks, 2001; Rose, 2002) que se dedicam ao assunto de modo mais aprofundado. As metodologias existentes para a análise imagética, e fotográfica em particular, incluem análise composicional, análise de conteúdo e análise discursiva, entre outras, a partir de metodologias que vão beber a fontes tão diversas quanto a história de arte, a semiologia e a psicanálise. Cada um destes métodos tem as suas virtudes e fragilidades. Como tal, a nosso ver, uma análise fotográfica que se diz séria e rigorosa deve assumir uma postura multidisciplinar, misturando diversos métodos de modo a compreender os significados detalhados, e por vezes contraditórios, que se articulam numa mesma imagem ou corpus de imagens. 
Numa mesma imagem encontramos sempre três possíveis subcampos de estudo distintos, que se articulam entre si. Estes são: 1) o campo da produção da imagem, ou seja, quem a criou, em que contexto, com que ferramentas, e com que objetivo; 2) o campo da imagem em si mesma, o seu conteúdo e composição visual; e 3) o campo da receção, de quem vê a imagem, os significados e usos que Ihe atribui (Rose, 2002). Apesar de uma investigação visual várias vezes optar por focar-se apenas no estudo de um destes subcampos, é no entanto reconhecido e aceite que nenhum destes em isolamento é capaz de criar um conhecimento integral e geral das imagens. O recurso a metodologias e abordagens variadas ajuda então a conciliar os contextos de produção, imagem e receção, considerando as suas interações, e procurando extrair um leque de significados socioculturais mais complexos.

Debruçando-se sobre o subcampo da produção, o investigador deve partir de interrogações como quem criou a imagem, qual a sua posição social e identitária, quando esta foi criada, onde, de que tecnologias beneficiou e quais as suas limitações... (Rose, 2002: 188) Tais questões, respondidas através da pesquisa de documentação histórica e de arquivos ou através de métodos mais tradicionalmente etnográficos como conversas ou entrevistas, providenciam contexto histórico-social à imagem.

Ao considerar o papel do fotógrafo recupera-se a concessão feita por Bazin ao seu papel na seleção do que fotografar. John Berger (1972b: 10) vê nesta simples escolha uma negação do caráter verdadeiramente mecânico e automático da fotografia; esta última passa a ser vista como encarnando um "modo de ver" específico do fotógrafo, sendo a escolha de fotografar um determinado objeto ou momento, de entre infinitos outros possíveis, um reflexo da sua subjetividade. Esta escolha é já em si mesma significativa e informativa para o investigador, revelando já significados, uma valoração inconsciente de determinados momentos em detrimento de outros. Pela sua inevitável seletividade a fotografia comporta já uma mensagem, uma mensagem que no seu primeiro nível de leitura afirma "Eu, o fotógrafo, decidi que isto merece ser fotografado." (Berger, 1972a) Assim, ao contrário das mitologias inconscientes do realismo fotográfico, constata-se que no fotográfico o real não se manifesta a si mesmo, intocado. A realidade é recortada, reenquadrada, manipulada pelas mais ínfimas escolhas técnicas de abertura de lente, velocidades, iluminação, filtros, etc. Através destas escolhas o fotógrafo torna-se parte integrante das fotografias e constrói o seu discurso.

Ainda no momento da produção fotográfica, também o sujeito fotografado ajuda a determinar o resultado final, assim como os seus possíveis significados, através de mecanismos performativos como a pose e a seleção dos contextos em que se permite

\footnotetext{
${ }^{1}$ Tradução da autora.
} 
a ser fotografado. É do interesse do sujeito, embora este nem sempre esteja consciente de tal, que a imagem o retrate no seu melhor, uma versão idealizada de si mesmo. Exceptuando casos de fotografia cândida ou ilícita, o ato fotográfico dá-se num acordo entre fotógrafo e fotografado, e assim que o sujeito se sente "olhado pela objetiva" este prepara-se para a imagem, metamorfoseando-se antecipadamente nesta (Barthes, 2008: 18-19). Estes comportamentos, a nossa quase-compulsão em sorrir para a foto, embora destinados a influenciar o resultado da imagem, dão-se na fronteira entre a conduta voluntária e involuntária que define o habitus, e expressam simultaneamente convenções sociais sobre o que é aceitável enquanto fotografia.

Assim, estas ditas manipulações e escolhas quer do fotógrafo quer do fotografado aquando da captação fotográfica não devem ser vistos como um engano, uma negação do real, mas sim como uma manifestação de hábitos e convenções que compõem o real-social, sendo que a análise destas manipulações é em si mesma significante.

Em relação à imagem em si mesma o investigador deve, no decurso de uma observação séria e prolongada, questionar-se sobre o que está a ser mostrado na imagem, em que elementos se focaliza a atenção numa primeira visualização e porquê, qual a relação estabelecida entre os diversos elementos da imagem, qual o impacto do uso da cor e qual os significados transmitidos pelos diferentes elementos da imagem e, também, pela imagem enquanto um todo (Rose, 2002: 189). Para tal o investigador recorre, num primeiro momento, a metodologias como a análise composicional, focando-se na forma e no conteúdo da imagem em si mesma para compreender a sua significância, uma metodologia herdada de disciplinas como a história de arte. Esta análise composicional é depois complementada com um questionamento semiótico, que olha cuidadosamente para os elementos da imagem enquanto signos e tenta compreender que significados estes comportam e geram, relacionando-os com sistemas mais vastos de conhecimento.

Paradoxalmente, ao analisar a imagem em si mesma, o investigador vê-se obrigado a considerar aquilo que está fora da imagem, aquilo que esta (por decisão do fotógrafo) não mostra. Desta relação entre o visível e o invisível, o presente e o ausente, emergem novos significados e leituras da fotografia (Berger, 1972a).

Finalmente, no subcampo da receção o investigador dedica-se a compreender quais os públicos originais e presentes da imagem, em que contextos esta é apresentada, que textos ou contextualizações a acompanham, como circula, que leitura faz este público desta, moldada por que convenções, e se estas leituras coincidem ou não com as intenções da sua produção (Rose, 2002: 189-190). Ao considerar os espetadores, alarga-se o campo da análise da imagem, trazendo um novo conjunto de fatores interpretativos que aceitam os "modos de ver" de um espetador concreto como tão ou 
mais importantes do que a imagem em si mesma. O modo como vemos algo, segundo Berger (1972b: 8), é afetado pelos nossos conhecimentos prévios e crenças. Assim, apesar de o conteúdo da imagem fotográfica estar "quimicamente fixo no papel"2, a sua interpretação flutua, cada espetador atribuindo novos significados consoante a sua experiência cultural e pessoal (Edwards, 1992: 8). Deste modo, metodologias e ramos de saber dedicados ao entendimento da psique humana, tal como a psicanálise, conjugam-se com a análise imagética para tentar compreender os efeitos da imagem no espetador e vice-versa. É também no campo da receção que o antropólogo visual se sente mais à vontade para recorrer a metodologias mais convencionais na antropologia, sendo bastante comum aplicar estratégias de observação participante e trabalho etnográfico nos contextos quotidianos de consumo dos média visuais (Coman \& Rothenbuhler, 2005: 2). Períodos extensos de observação contínua e recurso a entrevistas conversacionais ou estratégias de foto-elicitação são utilizados como modos de compreender os contextos imediatos, físicos, individuais e interpessoais da receção imagética.

\section{Os limites da fotografia}

É necessário, no entanto, ter uma clara noção das limitações da imagem fotográfica em si mesma e enquanto objeto para o estudo antropológico. Em primeiro lugar torna-se necessário enfatizar que todas as fotografias são, em maior ou menor grau, construídas e, como tal, comportam mensagens tendenciosas. O estatuto místico denotativo, de mensagem sem código perfeitamente análoga ao real e objetiva, que Roland Barthes (2009: 13-15) atribuiu à fotografia é imediatamente posto em causa ao reconhecer que a conotação, ou seja a atribuição de sentido à mensagem fotográfica, opera já nos momentos iniciais da sua produção, na escolha do que fotografar, no seu enquadramento, nos constrangimentos mecânicos e tratamento técnico, nos modos de apresentação da imagem, etc. As mensagens denotativa e conotativa da fotografia são indissociáveis, não existindo nunca, antes de qualquer leitura ou significação, uma fotografia pura, frontal e nítida, puramente denotativa.

O significado de uma fotografia está sempre inevitavelmente sujeito a uma moldura cultural, envolto num discurso fotográfico, que limita as suas possíveis funções, os seus significados e mesmo as nossas expectativas e leituras em relação a esta, e como tal deve ser encarado criticamente. A fotografia deve ser entendida dentro de uma história de convenções visuais centradas na busca do realismo mimético, que domina a cultura ocidental desde o Renascimento, e a nossa capacidade, vista como quase intuitiva, de

\footnotetext{
${ }^{2}$ Tradução da autora.
} 
ler uma fotografia advém de séculos de familiarização com convenções de perspetiva. Alan Sekula (1982: 85-86) exprime esta necessidade de aprendizagem de leitura fotográfica ao narrar a breve história do antropólogo Melville Herskovits que, no decorrer do seu trabalho de campo no sudoeste de África, mostra a uma mulher bosquímana uma fotografia do seu próprio filho. A mulher é, no entanto, incapaz de reconhecer o que quer que seja na imagem, até que o antropólogo lhe aponte e explique os seus detalhes. Desprovida da tradição visual que ensina a reconhecer na fotografia um análogo do real, para esta mulher a fotografia não era entendida como uma mensagem visual até ser contextualizada linguisticamente pelo antropólogo, com quem aprendeu a ler a fotografia. A leitura de uma fotografia depende então sempre de um saber do espetador (no nosso caso, profundamente enraizado e naturalizado), sem o qual esta seria apenas um aglomerado de linhas, formas e cores ininteligíveis.

Torna-se necessário evitar cair na ilusão da transparência fotográfica, de a ver como "uma janela transparente para o mundo"3 (Mitchell, 1984: 504), neutra e documental, e ver na prática fotográfica o resultado de um longo processo histórico e cultural, procurando reconhecer nas imagens os sinais das convenções que moldam a produção fotográfica e que implementam leituras preferenciais destas.

A imagem fotográfica oferece-nos enormes quantidades de informação visual, uma infinidade de detalhes sobre os quais o investigador pode-se debruçar durante horas ou dias a fio, contudo estas devem ser reconhecidas como apenas documentos parciais dos momentos e circunstâncias que retratam, oferecendo pouco em termos de significado. Ao contrário da memória humana - um processo altamente subjetivo e seletivo que retém de modo fragmentado determinados momentos devido à sua significância pessoal, indissociáveis do seu contexto - a fotografia capta indiscriminadamente todos os detalhes visíveis do momento, mas desprovidos de conteúdo (Kracauer, 1993: 425-426). Assim, a despeito da aparente plenitude oferecida pela fotografia, esta, destituída de contexto, oferece apenas a possibilidade de sentido, só se tornando verdadeiramente informativa quando inserida num discurso concreto.

Todas as referências contidas numa fotografia são-lhe, necessariamente, externas, e como tal os significados que lhe associamos são altamente dependentes de contexto e transientes, variando consoante o ambiente sociocultural em que são lidos (Banks, 2001: 10). Arrancada do seu contexto originário, a fotografia torna-se passível de vários usos arbitrários, revelando então uma multivocalidade inerente a toda a fotografia, que pode ser repetidamente recontextualizada e reinterpretada, comportando a possibilidade de múltiplas narrativas e múltiplas leituras, por vezes mesmo

\footnotetext{
${ }^{3}$ Tradução da autora.
} 
contraditórias. Contudo, os seus significados originais assim como o rol de significados que foi adquirindo e perdendo ao longo da sua circulação podem ser parcialmente recuperados através de uma cuidadosa investigação que tenha em conta a sua história e usos sociais. Tal pesquisa deve levar em conta quer a narrativa interna da fotografia, quer as narrativas externas que a rodeiam. A imagem, por si só, é insuficiente para restituir o momento fotografado, apenas permitindo um conjunto mais ou menos acertado de deduções e, como tal, temos que considerar a tradição oral que a rodeia, tendo sempre presente a falibilidade que também esta comporta (Kracauer, 1993: 423) Estratégias para tentar fixar os significados da imagem são frequentemente utilizadas e como tal devem ser tidas em conta pelo investigador. Entre elas destaca-se o recurso a informações textuais, títulos, descrições, contextualizações orais, como modo de atenuar a multivocalidade fotográfica e guiar uma leitura preferencial. Estes textos têm assim uma função elucidativa mas também simultaneamente repressiva (Barthes, 2009: 35), reduzindo a imagem ao texto.

A enorme reflexividade com que o antropólogo visual encara a imagem fotográfica deve também ser estendida à sua própria atividade, colocando em causa as suas perceções da realidade, de modo a evitar criar e condicionar o próprio objeto que se propõe a estudar (Augé \& Colleyn, 2008: 76). O investigador deve abandonar todas as ilusões de objetividade transcendente, a ideia de que está imune às influências da sua própria existência sociocultural e de que é meramente um observador externo, entrando no processo etnográfico de modo auto-consciente (Banks, 2001: 112). A sua própria perceção e capacidades interpretativas devem, tal como no caso do espetador, ser reconhecidas como histórica e culturalmente determinadas, procurando reconhecer o seu inevitável recurso a convenções naturalizadas de leitura. Todos os passos do processo de análise e escrita devem ser encarados com uma visão extremamente crítica, questionando-se constantemente, sem cair, no entanto, num extremo de dúvida paralisante.

A imagem fotográfica deve ser então encarada como uma produção histórica, social e cultural em curso, e não como uma entidade fechada. Uma análise dotada de um espírito antropológico deve considerar as suas relações com as diversas sociedades em que as imagens se manifestam, as suas relações com outras imagens, média e contextos, a constante evolução dos seus significados, nunca dando por concluída a relação entre o que vemos e o que conhecemos.

\section{Bibliografia}

Augé, M. \& Colleyn, J.P. (2008). A Antropologia. Lisboa: Edições 70.

Banks, M. (2001). Visual Methods in Social Research. Londres: Sage Press. 
Barthes, R. (2008). A Câmara Clara: Nota sobre a Fotografia. Lisboa: Edições 70.

Barthes, R. (2009). A Mensagem Fotográfica, in Barthes, R., O Óbvio e o Obtuso. Lisboa: Edições 70.

Bazin, A. \& Gray, H. (1960). The Ontology of the Photographic Image. Film Quarterly, Vol. 13, No. 4, 4-9.

Benjamin, W. (1999). Little History of Photography, in Jennings, M. W., Smith, G. \& Eiland, H. (eds.) Walter Benjamin: Selected Writings, Volume 21927 - 1934 (pp. 507530). Cambridge e Londres: The Belknap Press of Harvard University Press.

Berger, J. (1972a). Understanding a Photograph, in Berger, J. (ed.) Selected Essays and Articles: The Look of Things (pp.178-182). Harmondsworth: Penguin Books Consultado em:

http://www.macobo.com/essays/epdf/berger_understanding_a_photograph.pdf Berger, J. (1972b). Ways of Seeing. Londres: Penguin Books.

Berger, J. (1980). Uses of Photography, in Berger, J. (ed.) About Looking. Nova lorque: Pantheon Books.

Casanova, J. L. (1995). Uma Avaliação Conceptual do Habitus. Sociologia - Problemas e Práticas, Nº18, 45-68.

Coman, M. \& Rothenbuhler, E. W. (2005). The Promise of Media Anthropology, in Coman, M. \& Rothenbuhler E.W. (eds.) Media Anthropology. Califórnia: Sage Publications.

Edwards, E. (1992). Introduction, in Edwards, E. (ed.) Anthropology \& Photography: 1860-1920. New Haven e Londres: Yale University Press.

Kracauer, S. \& Levin, T. Y. (1993). Photography. Critical Inquiry, Vol. 19, No. 3, 421436.

Krauss, R. (1977a). Notes on the Index: Seventies Art in America. Part One. October, Vol. 3, 68-81.

Krauss, R. (1977b). Notes on the Index: Seventies Art in America. Part Two. October, Vol. 4, 58-67.

Krauss, R. (1984). A Note on Photography and the Simulacral. October, Vol. 31, 49-68. Mac Dougall, D. (1999). The Visual in Anthropology, in Banks, M. \& Morphy, H. (eds.) Rethinking Visual Anthropology (pp.276-295). New Haven e Londres: Yale University Press.

Malinowski, B, (1997). Os Argonautas do Pacífico Ocidental. Ethnologia, $n^{\circ}$ 6-8, 17-37. Mitchell, W. J. T. (1996). What Do Pictures "Really" Want". October, Vol. 77, 71-82. Mitchell, W. J. T. (1984). What Is an Image? New Literary History, Vol. 15, No. 3, Image/Imago/Imagination, 503-537. 
Morphy, H \& Banks, M. (1999). Introduction: Rethinking Visual Anthropology, in Banks, M. \& Morphy, H. (eds.) Rethinking Visual Anthropology (pp.1-35). New Haven e Londres: Yale University Press.

Rivière, P. (2011). Introdução à Antropologia. Lisboa: Edições 70.

Rose, G. (2002). Visual Methodologies: An Introduction to the Interpretation of Visual Materials. Londres: Sage Publications.

Sekula, A. (1982). On the Invention of Photographic Meaning, in Burgin, V. (ed.) Thinking Photography (pp.84-109). Londres: MacMillian Press.

Stiegler, B. (2008). Photography as the Medium of Reflection, in Kelsey, R. \& Stimson, B. (eds.) The Meaning of Photography (pp.194-197). Massachussetts: Clark Art Institute.

Sofia Caldeira licenciou-se em Arte e Multimédia na Faculdade de Belas Artes, Universidade de Lisboa. Fez uma pós-graduação em Realização na Restart e mestrado em Antropologia - Culturas Visuais na Faculdade de Ciências Sociais e Humanas, Universidade Nova de Lisboa. Trabalhou como investigadora teórico-visual para produções cinematográficas, mantendo paralelamente uma atividade de investigação independente em cultura visual. Presentemente, frequenta o doutoramento em Ciências da Comunicação, na Universidade de Gent, na Bélgica.

$\bowtie$ sofiapcaldeira@gmail.com 